\title{
Human Distribution in Caucasia in the Coldest and Driest Period of the Last Glacial
}

\author{
Alexandre Gavashelishvili \\ Ilia State University, 3/5 Cholokashvili ave., \\ Tbilisi, 0162, Georgia \\ aleksandre.gavashelishvili@iliauni.edu.ge \\ DOI: https://doi.org/10.52147/2667-9353/2021-1-84-95
}

\begin{abstract}
Since the period the modern human originated anatomically, genetic diversity was accumulated in the hereditarily transferred DNA (e.g., Y-chromosome and mitochondrial DNA), which makes it possible to estimate the ways of human origination and evolution. The research presented in the article uses the branches of $Y$-chromosome (or paternal branches) which originated in the period of the Last Glaciation. According to the hypothesis to be researched, the major phenomenon in the geological past which could have caused genetic differences by means of reproductive distancing of human populations (i.e., isolation) was the succession of minimal temperatures over the period of glaciation. The author's hypothesis was motivated by the fact that the dates of temperature minimums almost coincided with the times of origination of paternal branches presumed by other scholars (Fig. 1). Consequently, it was the distribution of the biomes during these minimums that must have affected creation and dissemination of paternal branches.
\end{abstract}

Key words: population, chromosome, paternal branch, biome

Introduction. Today humans live in almost every part of the earth; however, it has not always been like this. Technology, rather than adaptation by means of natural selection made humans occupy nearly all the biomes existing on the landform. In earlier times, humans possessing simpler technology occupied less biome, which is why they relied on particular climate and terrain more than they do today.

In anatomical terms, modern humans got separated from other hominids (presently extinct) in Africa about 200,000 years ago and started migrating to Eurasia during the last glaciation (i.e., 15,000120,000 years ago). In the process of migration, the area of human distribution changed with the change of climate: the area would expand during warm spells and reduce during cold ones.

In cold periods which were also characterized by droughts, areas of human distribution split into smaller areas far from each other (i.e., into refugia or shelters). In the coldest and driest spell of the Last Glaciation, so-called Last Glaciation Maximum (19,000-23,000 years ago), humans abandoned almost the whole northern Eurasia and took shelter in the refugia in the south of the continent. From the refugia they returned to the north during the warm spell following the glaciation maximum. These refugia and immigration barriers played an important role in the human evolution which also caused formation of the human genetic and ethno-linguistic system existing in the world today. Therefore, knowledge of situation of the refugia is important for understanding present genetic structure of a human. Although radiometrically dated sites of human settling during the Last Glaciation have been studied (employing the method of climate reconstructions and various models) in order to estimate the ecological niche and spatial distribution of humans, none of the studies looks at the interrelation between the human and the environment in the context of populational genetics, (2) the studies clearly demonstrated interaction between the human and the biome and (3) encompassed the whole world.

Since anatomically modern humans originated, genetic diversity has been accumulated in the 
clonally transferred hereditary DNA (e.g., Y-chromosome and mitochondrial DNA), which allows us to estimate human origination and the ways of human origination and evolution. In our research we used Y-chromosome branches (paternal branches) that emerged in the period of the Last Glaciation. According to the hypothesis we are studying, in the geological past the major event which could have caused genetic differences by reproductive distancing of human populations (i.e., isolation) was the succession of minimal temperatures over the period of glaciation. Our hypothesis was motivated by the fact that the dates of temperature minimums almost coincided with the times of emergence of paternal branches presumed by other scholars (Fig. 1). Accordingly, it was the distribution of the biomes during these minimums that must have affected creation and dissemination of paternal branches.

Figure 1. Temperature variation $\left(C^{\circ}\right)$ in the ice core of Vostok Station during the last 160,000 years and average age of divergencies (origination of branches) of human $\mathrm{Y}$-chromosomes in the last period of glaciation.

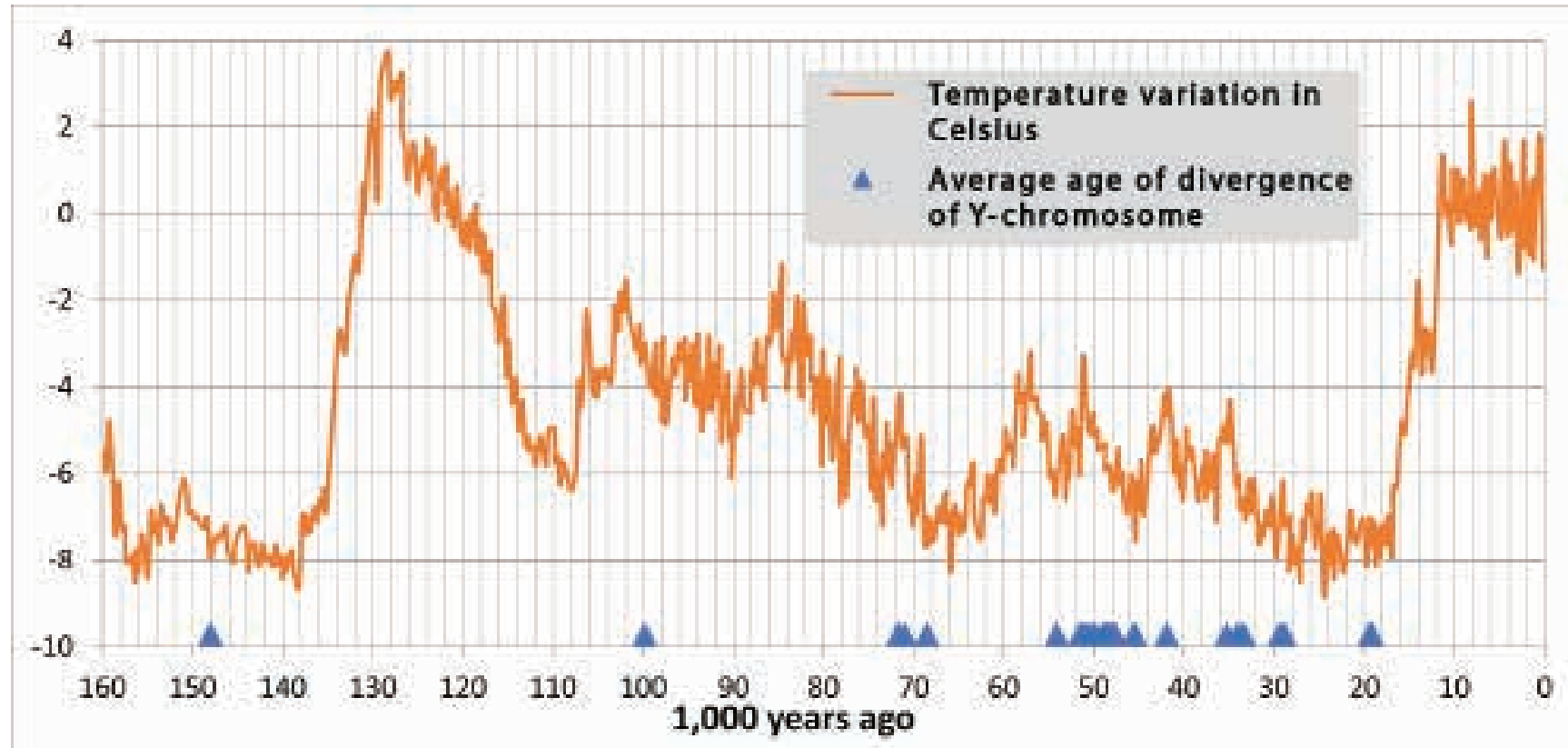

\section{Temperature variation in Celsius}

\section{Average age of divergence of $Y$-chromosome}

In our study (Gavashelishvili and Tarkhnishvili 2016) we tried to reveal biomes of glaciation (ecosystems) where human source populations survived and paternal branches originated. In order to do so, first we produced the model of permanent rivers based on the data of present hydrographic network, climate and relief, and expanded it through the Last Glacial Maximum as the latter being one of the representatives of temperature minimums of glaciation. Then we modeled distribution of glaciation biomes. It was made possible by connecting glaciation climate and proximity of permanent rivers to the places of the period of glaciation where other scholars had already identified the biomes through the pollen of fossilized plants and other waste. In order to reveal the areas from the modeled biomes where paternal branches were likely to have originated, we hypothesized that (1) present distribution 
of diversity of these branches largely depends on geographic remoteness from these places, (2) their situation coincides with the recognized areas of origination of paternal branches and (3) settlement sites of glaciation period humans are largely accumulated in these areas. Fig. $\mathbf{2}$ shows our workplan for identifying these places. We did not use mitochondrial branches (maternal branches) as additional source for examining our hypothesis, because maternal branches have very weak phylogeographic signal (structure). The reason for this could be weak female territoriality and/or a numerical predominance of women over men which causes more rapid random accumulation of distinctive genes in the male population. Our model demonstrated an important role of the glacial period in creating modern human genetic structure and ethnogenesis considering landscape types and climate change.

(1) Present hydrographic data / Present climate data / Present relief and dampness accumulation data

(2) IGM climate data / Permanent river model / LGM relief and dampness accumulation data

(3) IGM map of permanent rivers >distance from river / LGM climate data / LGM fossilized plant data /

(4) IGM map of biomes > variants > aggregation

(5) Geographical distance from LGM biomes / Present NPP / Present Y-DNA diversity / Present NPPH / Present human density

(6) Places of origination of Y-DNA branches

(7) Paleolithic settlement sites

(8) Coincidental biomes / Valid biomes / Present Y-DNA diversity model

Biomes of glaciers where human source populations survived and Y-DNA branches originated.

\section{Methods:}

1. Modeling of a permanent river by binomial logistic regression;

2. Launching of a permanent river model on LGM data;

3. Modeling of IGM biomes through CRT;

4. Hypothesis 1: present Y-DNA diversity and LGM biomes;

5. Least squares regression;

6. Hypothesis 2: coincidence analysis;

7. Hypothesis 3: calculation of settlement selection index;

8. Comparison of results for consensus.

LGM - Last Glaciation Maximum

CRT - Classification and Regression Trees

NPP - Net Primary Production

NPPH - Net Primary Production available for Humans 


\section{Body. 2. Methods. 2.1. Biomes during the Last Glaciation Maximum}

In order to model the biomes of the Last Glaciation Maximum, we linked paleo-plant reference data (http://www.bridge.bris.ac.uk/resources/Databases/BIOMES data) with paleoclimate data (http:// www.worldclim.org) and proximity of permanent paleo-rivers. In the final model we pointed out eight classes of biomes: (1) tropical forest, (2) warm temperate forest, (3) temperate forest, (4) taiga, (5) dry rare forest, (6) grassland and shrubland, (7) desert and (8) tundra. In modeling we used Bailey's effective temperature and moisture index (i.e., correlation between annual precipitation and Bailey's effective temperature). Apart from climate data, we used digital elevation models - both modern and that of the land in glacial period - in the modeling of paleo-rivers.

The majority of existing models of paleo vegetation is based on local climate data and ignore importance of hydrologic drainage systems in the process of formation of plant communities. For example, without considering the latter, none of the models is able to explain why there are large groves in dry places. Since the existing hydrographic data of glaciation were inaccurate for our objectives, first we produced the model of permanent rivers from present conditions and then extended it over the climate and relief data of glaciation (Fig. 2). Probability of location of paleo river systems were calculated from the interaction of two variables: (1) moisture accumulation surface and (2) moisture accumulation. The first reflects the whole catchment area above the given place, the second shows possible amount of water flow, i.e., the first reflects water flow loss caused by infiltration, friction and evaporation, while the other variable promotes retention of water flow. Variables of moisture accumulation were calculated from climate and relief data. For the model the information about constancy of water flow was taken from the existing database called VMAPO (source: http://www.mapability.com). Digital maps of the base show the water flow by dotted lines. 80,000 points were scattered on these lines so that distance between these points was over $5 \mathrm{~km} .40,000$ of the points were laid out on the continent of America, and the other 40,000 - across the rest of the world in order to receive the model, or for calibration. Each of these two geographic groups encompassed 20,000 points over the permanent flow and 20,000 - over the non-permanent flow. The model was tested both in space and time. To do so, we compared it with paleo-hydrological and hydraulic model of the Sahara Desert 124,000-125,000 years ago (http://journals. plos.org/plosone/article?id=10.1371/iournal. pone.0074834).

The model of probability of the river permanency was produced through logistic regression from the data obtained in the above-mentioned points. Permanent paleo rivers were taken out from this model by the ultimate probability indicator which equated sensitivity and specificity of the model. Distance from the rivers received in such a way were used for modeling biome distribution. Using the method of classification tree, the biomes of the Last Glaciation Maximum were linked to the appropriate climate and proximity of permanent rivers.

In our research all the data were spatially processed through ArcGIS Desktop v.9.3 program, while multi-variable statistical procedures were conducted on these data by means of the algorithms of IBM SPSS Statistics v.21 program. It applies to the following sub-chapters of the methods too.

\subsection{Present genetic human diversity and glacial biomes.}

If the biomes hypothesized by us had actually covered the places that sheltered humans, it must be reflected in geographical distribution of genetic diversity of humans and the evidence to this geographical distribution must be reflected in present human populations. After presuming the distribution of biomes during the Last Glaciation Maximum (i.e., from the temperature minimums of the last glaciation to the coldest and driest spells), we analyzed present diversity of paternal branches origi- 
nated during the Last Ice Age in terms of the presumed biomes. It was hypothesized that if there had been reproductively isolated places where these $\mathrm{Y}$-chromosome branches originated in the periods of climate deterioration of the Last Glaciation, then there is high likelihood that present distribution of the diversity of these branches is the function of geographic distancing from this place or refugium. We presumed that if there were reproductively isolated areas where these Y-chromosome branches originated during the periods of climatic deterioration during the last glaciation, it is highly likely that present distribution of the diversity of these branches is the function of geographic distancing from each of the areas or refugia. The essence of this presumption is that the humans that left refugia would have occupied non-refugia situated closer to the refugia more rapidly and, as a consequence, larger genetical diversity would have been accumulated in non-refugial areas if its average distance from genetically different refugia is shorter. According to this speculation, we considered the cluster of biomes that would best explain present distribution of the diversity of paternal branches to be refugia. Thus, we received a total of 254 clusters out of all the possible combinations with 1 to 7 biomes (we had 8 biomes on the whole).

Among the present different ethnic groups and populations frequencies of the paternal branches that originated during the Last Glaciation were received from a lot of published material. These branches are: $A 2, B, C, D, E, G, H, P, M S, L, T, I, J, N, O, Q, R$. On the whole, 48 populations were received. Branch diversity in each population was estimated in quantitative terms according to Nei's nucleotide diversity index which implies not only branch frequency, but also genetic distance between branches. In order to estimate the relationship between genetic diversity and proximity of refugia we measured geographic distances between population centroids and the edges of possible refugia (out of the conjectural refugia situated in Africa, Eurasia and Australia, as humans survived glaciation on these continents).

For geographic distances we took both Euclidean (or straight-line distance) and the simplest distance. The latter is calculated considering obstacles. We used slope inclination and food scarcity as obstacles, because we decided that human distribution and mixing of populations largely occurred and still occurs in the climate conditions that are similar to the present day. Slope inclination was calculated from the digital elevation model (http://www.gebco.net). As for food scarcity, we took inverse net primary production efficiency. Net primary production was calculated with Schur model, which uses two exponent functions of annual average temperature and summary precipitation. We improved the Schur model by entering hydrological drainage index in it. To do so we calculated net primary production in the places where our river model showed permanent water flow only with Schur temperature function, because in such places what limits accumulation of biomass is only temperature, but not water. In order to separate the part of net primary production that human consumes better, i.e., net primary production available to humans, we multiplied it by the share of woodless area. By this we reduced the production in accordance with how densely wooded the area was. We did so because, according to different studies, present-day hunter-gatherers obtain the least food in forest biomes. Forest vegetation portion was received from satellite data (NASA: http://www.echo.nasa.gov/reverb/ about reverb.htm). While calculating the simplest distance, we considered large bodies of water (e.g., seas, oceans), permanent swamps, permanent snowfields and glaciers as obstacles impenetrable for humans. We did not consider the Suez Canal, the Bosporus, straits of Sunda and Sahul., straits of Japan, the Bering Strait and the Panama Strait. Dependence of the present-day diversity on summary proximity of conjectural refugia was estimated by means of least square regression. In addition, we tested other possible predictors: modern net primary production, human density, slope inclination, elevation and both Euclidean and simplest distances from conjectural refugia. All the listed variableexcept for geographical distancing were average quantity calculated in the area of each population. 


\subsection{Areas of origination of genetic branches considering the biomes of glaciation}

Areas of origination of some paternal branches have been estimated through phylogeographic hypothesis based on the current geographical distribution of genetic variability. For our analyses we used only the hypotheses received as a result of common consensus. Mapped and textual descriptions of these areas of origination were transformed into polygons (i.e., were digitally mapped). The closest probable refugia were pointed out for each polygon according to the distance between the center of the polygon (i.e., centroid) and the edge of the refugium. This distance was considered the reference point (zero) if the center fell in the refugium. Then the polygons of origination were counted in order to provide quantitative estimation of spatial coincidence with the clusters of probable refugia and places of origination. We found that the lower the index, the higher the coincidence. For instance, if all the polygons of origination share the closest probable refugium, it is the worst coincidence, but if a unique closest refugium falls in each polygon, it is the best coincidence. If more than one cluster of probable polygons exposed the same coincidence index, we chose the one whose average distance between the polygons and the closest probable refugia was the shortest. Thus, we considered the cluster with the best spatial coincidence index to be a refugium.

\subsection{Human settlements during the Last Glaciation}

We analyzed location of the human settlements of the period of the Last Glaciation Maximum in relation to the biomes hypothesized by us. For this we used radiometrically dated geographical coordinates of the settlements of anatomically modern humans. These data were sought in abundant published material. For the period in question, we received 127 settlement sites across the world. Dependence of these settlements on a certain biome was assessed by Jacob's index of habitat preference. Values of this index vary between -1 and +1 : negative values show invalidity of habitats, positive ones - validity of habitats. We considered the cluster of biomes with settlements that showed the highest value of Jacob's index of habitat preference.

\section{Outcomes}

Our hydrological model turned out to be rather accurate in spatial terms: it identified the majority of both practiced and trial points correctly (Tab. 1). It turned out to be quite accurate in time as well: location of the permanent rivers hypothesized by our model exactly coincided with those existing in the Sahara Desert 124,000-125,000 years ago which had been estimated by the paleohydrological and hydraulic model. 
Table 1. Binomial logistic regression model of permanent river probability $\left(R^{2}=0.537\right): P=1 /[7802.4$ $\left.\left(X_{1}+1\right)^{1.324} /\left(X_{2}+1\right)^{1.754}+1\right]$, where $X_{1}$ is moisture accumulation surface (calculated from the digital elevation model), while $\mathrm{X}_{2}$ is moisture accumulation (calculated from the digital elevation model and moisture index)

\begin{tabular}{|c|c|}
\hline P Balance ultimate indicator & P $>0.47$ \\
\hline \multirow{3}{*}{ Correctly identified \% of permanent flow } & Practiced in ancient world \\
& Tested in modern world \\
& 82.9 \\
\hline \% of correctly identified seasonal flow & Practiced in ancient world \\
& 84.1 \\
& Tested in modern world \\
& 84.5 \\
\hline Total \% of correct identification & Practiced in ancient world \\
& 84.1 \\
& Tested in modern world \\
& 83.7 \\
\hline AUC & Practiced in ancient world \\
& 0.875 \\
& Tested in modern world \\
& 0.856 \\
\hline
\end{tabular}

The model of the biomes of the Last Glaciation Maximum received with the method of classification tree (Tab. 2 and 3) made correct identification of $65 \%$ of the whole sample which covered both practice and trial points. Correct identification of each biome varied between $40 \%$ and $90 \%$. The method made the best identification of the tundra, while the worst area was grassland and shrubland. Out of the rest of the biomes the forest was better identified and its accuracy varied between $63.3 \%$ and $75 \%$. The index of correct identification of all the biomes exceeded that of incorrect one. Distance from permanent rivers explained $8.5 \%$ of the whole classification; specifically, it explained presence of forests in dry areas, where there were 10 points of tropical forests, 7 points of warm temperate forests, 5 points of temperate forests and 4 points of taiga. Moisture index reflected density of the biome in the given temperature, i.e., it divided biomes according to forests, savannahs, steppes and deserts. However, Bailey's temperature explained climate zones: tropical, warm, mild, subarctic and arctic. 
Table 2. Classification tree model (CRT) of biome demands during the Last Glaciation Maximum $(23,000$ $-19,000$ years ago).

\begin{tabular}{|c|c|c|c|c|}
\hline $\mathrm{N}$ & Biome & $\begin{array}{c}\text { Effective tempera- } \\
\text { ture }\left({ }^{0} \mathrm{C}\right)\end{array}$ & Moisture $\left(\partial \mathrm{\partial} /{ }^{\circ} \mathrm{C}\right)$ & $\begin{array}{l}\text { Distance from per- } \\
\text { manent river }(\mathrm{km})\end{array}$ \\
\hline \multirow{2}{*}{1} & \multirow{2}{*}{ rainforest } & $>16.603$ & $>100.806$ & \\
\hline & & $>16.603$ & $<=100.806$ & $\overline{<1}$ \\
\hline \multirow{2}{*}{2} & \multirow{2}{*}{$\begin{array}{l}\text { Warm temperate } \\
\text { forest }\end{array}$} & $\underset{<=16.603}{>} 13.698$ & $>100.806$ & \\
\hline & & $\begin{array}{c}> \\
<=16.603\end{array}$ & $<=100.806$ & $<1$ \\
\hline \multirow{2}{*}{3} & \multirow{2}{*}{ Temperate forest } & $\begin{array}{c}> \\
<=13.698\end{array}$ & $>100.806$ & \\
\hline & & $\underset{<=13.698}{>} 11.488$ & $<=100.806$ & $<1$ \\
\hline \multirow{2}{*}{4} & \multirow{2}{*}{ Taiga } & $\begin{array}{c}> \\
<=11.488\end{array}$ & $>100.806$ & \\
\hline & & $\begin{array}{c}> \\
<=11.488\end{array}$ & $<=100.806$ & $<1$ \\
\hline 5 & Sparse dry forest & $>10.568$ & $\underset{100.806}{>} 58.204<=$ & $>=1$ \\
\hline 6 & Grassland-shrubland & $>10.568$ & $\underset{58.204}{>38.358<=}$ & $>=1$ \\
\hline 7 & Desert & $>10.568$ & $<=38.358$ & $>=1$ \\
\hline 8 & Tundra & $<=10.568$ & & \\
\hline
\end{tabular}


Table 3. Error matrix of classification tree (CRT) biomes model by the Last Glaciation Maximum $(23,000-$ 19,000 years ago). Trial and practice points are combined.

\begin{tabular}{|c|c|c|c|c|c|c|c|c|c|}
\hline \multirow[b]{2}{*}{ Empirical } & \multicolumn{8}{|c|}{ Modeled } & \multirow[b]{2}{*}{ Total } \\
\hline & $\begin{array}{c}\text { Tropical } \\
\text { forest }\end{array}$ & $\begin{array}{c}\text { Warm } \\
\text { temperate } \\
\text { forest }\end{array}$ & $\begin{array}{c}\text { Temperate } \\
\text { forest }\end{array}$ & Taiga & $\begin{array}{l}\text { Sparse dry } \\
\text { forest }\end{array}$ & $\begin{array}{c}\text { Grass- } \\
\text { land-shru- } \\
\text { bland }\end{array}$ & Desert & Tundar & \\
\hline $\begin{array}{c}\text { Tropical for- } \\
\text { est }\end{array}$ & 17 & 2 & 1 & 0 & 1 & 2 & 0 & 0 & 23 \\
\hline $\begin{array}{l}\text { Warm tem- } \\
\text { perate forest }\end{array}$ & 4 & 15 & 0 & 1 & 0 & 0 & 0 & 0 & 20 \\
\hline $\begin{array}{c}\text { Temperate } \\
\text { forest }\end{array}$ & 1 & 3 & 36 & 1 & 1 & 1 & 0 & 8 & 51 \\
\hline Taiga & 0 & 0 & 0 & 7 & 0 & 0 & 0 & 4 & 11 \\
\hline $\begin{array}{l}\text { Sparse dry } \\
\text { forest }\end{array}$ & 0 & 0 & 4 & 0 & 26 & 1 & 2 & 6 & 39 \\
\hline $\begin{array}{c}\text { Grassland and } \\
\text { shrubland }\end{array}$ & 1 & 2 & 3 & 1 & 16 & 37 & 15 & 18 & 93 \\
\hline Desert & 0 & 0 & 0 & 0 & 1 & 2 & 5 & 3 & 11 \\
\hline Tundra & 0 & 0 & 2 & 0 & 0 & 0 & 5 & 62 & 69 \\
\hline Total & 23 & 22 & 46 & 10 & 45 & 43 & 27 & 101 & 317 \\
\hline
\end{tabular}


Selective least squares regression showed that the only variable which best explained variability of present diversity of paternal branches was the average simplest distance from sparse dry forests of glaciation whose resistance was determined by scarcity of net primary production available to humans. In mathematical terms, the regressive model is $\left(R^{2}=0.407\right)$ :

$\pi=(-5.351 \mathrm{E}-007 * \mathrm{X})+0.147$, where $\mathrm{X}$ is the average simplest distance from sparse dry forest refugium to the production available to humans.

Well-known places of origination of paternal branches perfectly matched with distribution of sparse dry forests of glaciation in spatial terms. Out of 12 areas of origination, 8 accommodated the nearest unique refugia.

The majority of the settlement sites of the Last Glaciation Maximum fell in the sparse dry forest (Tab.4). Density of settlements in this biome was much higher that in other biomes. Jacob's index of habitat preference also pointed to the fact that during glaciation hunter-gatherers gave preference to this biome. According to this index, humans avoided tropical forests, warm temperate forests, taiga, deserts and tundra.

Table 4. Distribution of human settlement sites in relation with biomes during the Last Glaciation Maximum $(23,000-19,000$ years ago).

\begin{tabular}{|c|c|c|c|}
\hline Biome & Frequency & $\mathbf{\%}$ & Habitation preference index \\
\hline Tropical forest & 1 & 0.787 & -0.754 \\
\hline Warm temperate forest & 0 & 0 & -1 \\
\hline Temperate forest & 8 & 6.299 & 0.655 \\
\hline Taiga & 0 & 0 & -1 \\
\hline Sparse dry forest & 78 & $\mathbf{6 1 . 4 1 7}$ & $\mathbf{0 . 8 6 2}$ \\
\hline Grassland-shrubland & 22 & 17.323 & 0.371 \\
\hline Desert & 7 & 5.512 & -0.780 \\
\hline Tundra & 11 & 8.661 & -0.747 \\
\hline Total & 127 & 100 & \\
\hline
\end{tabular}

Mapping of our model showed that in the coldest and driest spell of the last glaciation humans in Caucasia mainly lived in its western part, specifically, in Colchis (Fig. 3). 
Fig. 2. Modeled biomes in Caucasia during the Last Glaciation Maximum $(23,000-19,000$ years ago). During this period humans mainly lived in sparse dry forests (indicated red).

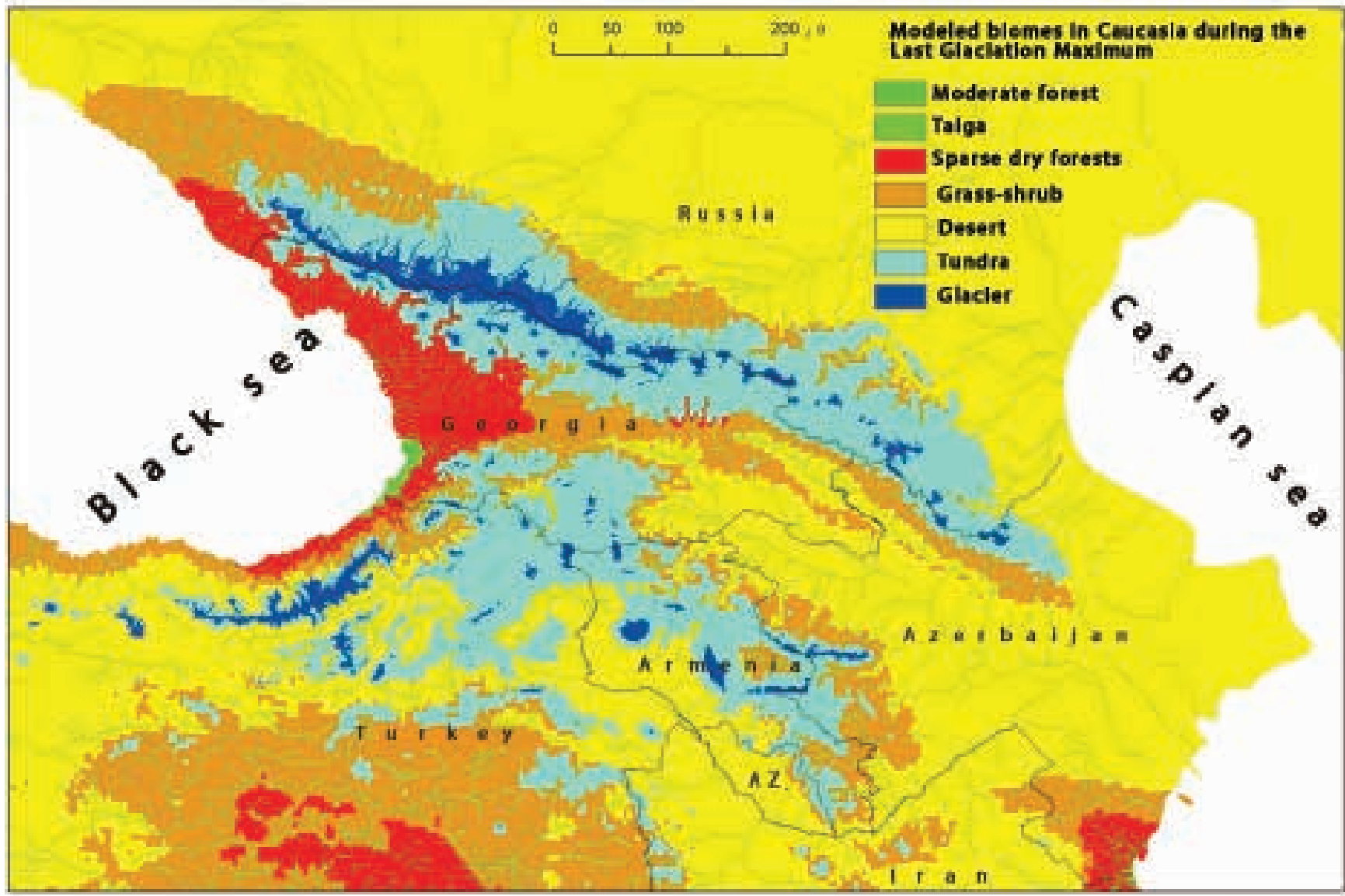

\section{Discussion and conclusions}

We restored the picture of what biome distribution was like during the Last Glaciation Maximum based on the data of fossilized plants, climate and relief. Our model of biomes correctly identified the majority of empirical data. Difference of the empirical and hypothesized data can be explained by the errors found in climate and drainage system reconstructions and in defining biomes from fossilized data. Nevertheless, it is the best model of biomes which we managed to receive thanks to existing data. All three different approaches (hypothesis) of ours in discovering human refugia demonstrate that sparse dry forest is the refugium where different paternal branches originated.

According to our first approach, during mild climate human expansion mainly occurred via the areas of high production (i.e., in places with a lot of food) and avoiding dense woods. Our second approach shows that well-known areas of origination of paternal branches were covered by sparse dry forests during the periods of temperature minimums of glaciation.

Our third approach too, which relied on the distribution of settlement sites during the Last Glaciation Maximum, showed that humans gave strong preference to living in sparse woodlands. Our results do not indicate that at the time humans lived only in sparse dry woodlands. They would probably end up in other biomes seasonally or lived there permanently, but less densely. Interpretation of our results is more presumable according to Pulliam's source-pond metapopulation model, where the 
refugia covered with sparse dry forests are sources of human population, while the rest of the biomes are population ponds. It must have been like this, because before humans developed technologies sufficient for adopting and transforming other biomes, sparse dry forests provided (1) more production (food) available for humans than thick forests and (2) more wood than open areas like grassland and shrubland. Humans definitely needed both food and trees. Apart from food, trees provide shelter from bad weather, protection from aggressive animals and material for housing, weapons and fire. Fire, in itself, provided protection from predators, warmth and easily digestible and disinfected food. Due to spears, bows and arrows made of wood smaller groups of humans and separate individuals hunted big animals efficiently, which ensured more meat intake and better protection. It is not excluded that in other biomes humans suffered from more infection carrier biters. Thus, because of the above listed reasons, sparse dry forests ensured more sustainable human populations than other biomes.

According to our finds, during the deterioration of climate in the Last Glaciation, especially during its maximum, the subsistence area of hunter-gatherers of the Paleolithic epoch (Stone Age) was extremely fragmented. Humans living in convenient areas were completely or partly isolated from each other. This spatial isolation promoted genetic drift (i.e., accumulation of random genetic differences among populations). Our model shows the largest spatial distance between sub-Saharan Africa, western Eurasia, Indian subcontinent, eastern Asia and Australia. As is known, today these continents are inhabited by the populations significantly different from each other. Study of 650,000 polymorphic areas of autosome single nucleotide showed that peoples' genetic difference between these subcontinents is bigger than that inside each of them. Moreover, location of these five subcontinental refugia coincides with the regions of domination of five major continental phenotypes. These subcontinents are linguistically different too, especially on the level of linguistic macrofamilies which originated during the Last Glaciation. However, spatial compatibility of these continents with languages is lower than with genotypes and phenotypes. This is probably so because languages can rapidly be completely (or almost completely) substituted by other languages while substitution of genes occurs gradually. Final conclusion of our research is as follows: (1) present-day genetic, phenotypical and linguistic differences are strongly related to the spatially isolated humans' refugia covered by sparse dry forests during the Last Glaciation and (2) these differences have been impossible to erase even by integration of many populations of the world into ethnic and political units.

\section{Reference}

Gavashelishvili, A. \& Tarkhnishvili, D. (2016) Biomes and human distribution during the last ice age. Global Ecology and Biogeography 25: 563-574. 